\title{
Vulnerability of resource users in Louisiana's oyster fishery to environmental hazards
}

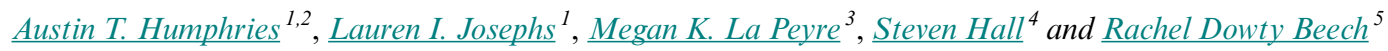

\begin{abstract}
Knowledge of vulnerability provides the foundation for developing actions that minimize impacts on people while maximizing the sustainability of ecosystem goods and services. As a result, it is becoming increasingly important to determine how resource-dependent people are vulnerable to environmental hazards. This idea is particularly true in coastal Louisiana, USA, where the current era of rapid land loss has the potential to undermine oyster fisheries. However, little is known about how such environmental change might differentially affect resource users and stakeholders. We examined social components of vulnerability to environmental hazards using indicators of susceptibility and adaptive capacity within the oyster fishery of Terrebonne Parish, Louisiana. Specifically, we used structured interviews to compare three resource-user roles: oyster fishers, oyster fishers/lease owners, and oyster lease owners only. Results indicated that oyster fishers/lease owners were highly dependent and thus susceptible to changes in the fishery because of high levels of occupational identity. These same people, however, were the most adaptable to change, which was reflected in their willingness to learn about new practices and evolve over time. Higher susceptibility in this group was offset by an increased ability to adapt, cope, and respond to changes in the environment. In contrast to these findings, oyster fishers that did not own any portion of a lease or business in which they operated were bad at coping with change and frequently held negative or fatalistic views on financial planning. These attributes made them the most vulnerable to environmental hazards. Overall, the most vulnerable participants in the Terrebonne Parish oyster fishery were those with low to moderate levels of personal and financial buffers and trust, coupled with high occupational identity and a low motivation to change. Local policy actions that target these attributes are likely to be the best entry points to reducing the vulnerability of stakeholders to hazards.
\end{abstract}

Key Words: adaptation; Crassostrea virginica; fisheries; Gulf of Mexico; management; shellfish

\section{INTRODUCTION}

Coastal communities are profoundly affected by environmental hazards and change. For example, redistributions of fisheries yields as a result of climate change are affecting coastal nations more than others (Allison et al. 2009, Chueng et al 2010). In places like Louisiana, USA, many coastal communities are dependent on renewable natural resources such as oysters. In fact, oysters account for \$67 million USD in dockside sales in Louisiana, making that state the leading provider of oysters in the United States (LDWF 2018). Beyond acting as an economic force, oysters provide a multitude of services not captured in the traditional marketplace (Coen et al. 2007, Beck et al. 2011). These include shoreline protection from erosion, water quality improvements, and provision of cultural or spiritual heritage. Rapid environmental change has the potential to bring about negative effects on these ecosystem services and cause major disruption to local livelihoods. In particular, oyster fisheries in the Gulf region are threatened by environmental change brought on by large sediment and freshwater diversions, which lead to prolonged periods of low salinity and sedimentation; hurricane events, which lead to harmful levels of saltwater intrusion; and oil spills, which lead to hypoxic conditions. These events represent environmental hazards that pose risks to people and nature. Thus, disaster risk management is a useful framework for discussing impacts and adaptation. Risk management frameworks specific to climaterelated events (e.g., IPCC 2012, 2014) state that adverse effects result when socially constructed conditions of vulnerability are exposed to physical hazards. Although not all environmental hazards facing the Gulf region are directly caused by climaterelated events (e.g., freshwater diversions), the mechanisms are similar, and a risk management framework is applicable.

Communities along the Gulf of Mexico coastline have been identified as among the most vulnerable to changes in oyster habitat in the United States (Ekstrom et al. 2015). The likelihood of hazardous environmental events coinciding with vulnerable social conditions means that these communities have a high disaster risk (IPCC 2012). Although interest in developing mitigation measures is increasing among local governments, necessary resources remain limited at the local level (Moser and Ekstrom 2011). Appropriate allocation of limited resources requires an understanding of how best to assess place-specific vulnerability, an area of research that remains understudied (Moser and Ekstrom 2011, Preston et al. 2011). Where spatially explicit vulnerability assessments have been undertaken, most have been at a larger (national) scale or relied on secondary census data (e.g., Emrich and Cutter 2011, Frazier et al. 2014, Ekstrom et al. 2015, Frigerio and De Amicis 2016; but see Kok et al. 2016). This scale of study may lead to unclear pathways to adaptation for local agencies charged with reducing vulnerability of individuals that have different risk attributes. Also, by aggregating all individuals within an entire county or zip code, vulnerability assessments and adaptation planning are in jeopardy of excluding individuals with attributes that may not align with the majority,

${ }^{1}$ Department of Fisheries, Animal and Veterinary Sciences, University of Rhode Island, Kingston, RI, USA, ${ }^{2}$ Graduate School of Oceanography, University of Rhode Island, Narragansett, RI, USA, ${ }^{3}$ U.S. Geological Survey, Louisiana Fish and Wildlife Cooperative Research Unit, School of Renewable Natural Resources, Louisiana State University Agricultural Center, Baton Rouge, LA, USA, ${ }^{4}$ Department of Biological and Agricultural Engineering, North Carolina State University, Raleigh, NC, USA, ${ }^{5}$ Emergency Management Program, University of New Haven, New Haven, CT, USA 
Fig. 1. Location of Terrebonne Parish, Louisiana, USA, including Houma, the location of the parish seat.

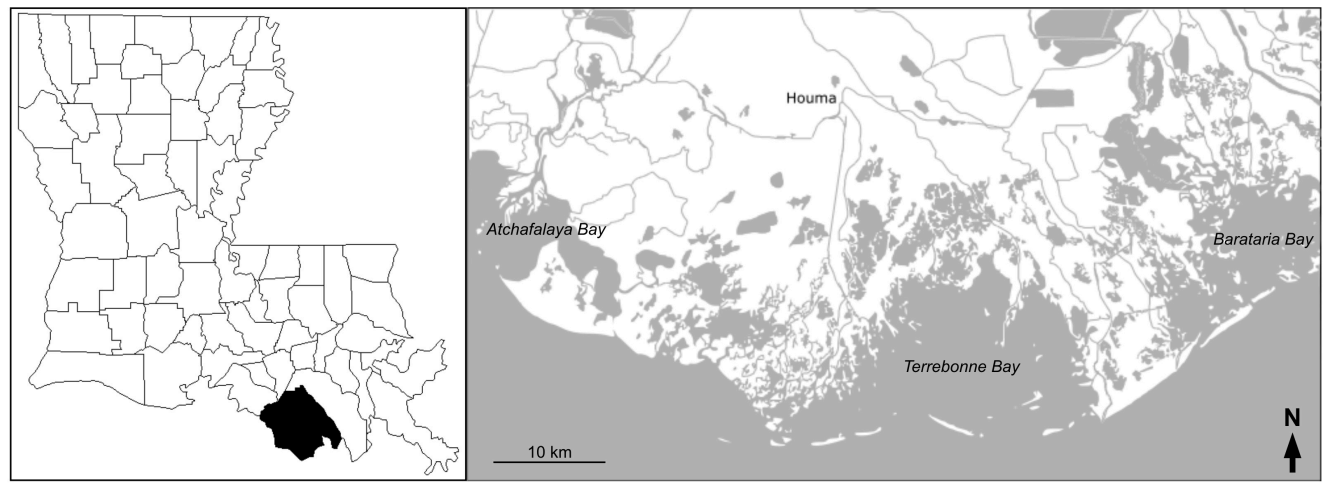

further increasing inequality (Cinner et al. 2015). One purpose of our case study is to use primary data directly from stakeholders to build a localized vulnerability profile of individuals. Thus, we hope to provide data for local management to be proactive in adaptation planning for climate change and hazards. By doing this, we were also able to determine if sources of vulnerability can be different within a single community or even within a single fishery, something that previous research using secondary data has not explored.

Previous works synthesizing vulnerability frameworks have identified that the disaster risk posed to people by environmental hazards is a product of their level of exposure, their susceptibility, and the degree to which they are able to cope with or respond to changes that occur (hereafter, adaptive capacity; Turner et al. 2003, Eakin and Luers 2006, Birkmann et al. 2013, IPCC 2014). While exposure and susceptibility inform the potential effects of a particular risk, adaptive capacity can have a profound effect on what impact actually occurs; knowing the degree to which adaptive capacity may offset susceptibility allows managers to understand better the difference between potential and actual social impacts of environmental hazards (Marshall and Marshall 2007, Marshall et al. 2013). Thus, efforts to reduce harm caused by environmental hazards take a number of forms that may focus on reducing a community's or individual's exposure and/or susceptibility, bolstering adaptive capacity, or some combination of these. However, because of the scale and complexity of tackling exposure (e.g., increases in ocean temperature), emphasis is often placed on management to address susceptibility and adaptive capacity (Cinner et al. 2012). Any such management action requires an understanding of the degree to which people are affected by environmental hazards and the ability of people to respond to or cope with resulting change.

Nonclimatic factors contribute to differences in vulnerability (IPCC 2014), in some cases, more strongly than environmental inputs (Siegel et al 2019). At the national and regional scales, some socioeconomic factors act as indicators of vulnerability with a degree of consistency, such as resource dependency and occupational flexibility (Adger 1999, Marshall et al. 2007, Hughes et al. 2012). However, sources of vulnerability have also been shown to be socially disaggregated and differ significantly between countries and within individual communities. For example, a study of Kenyan fishing communities examined vulnerability across social classes to reveal lower adaptive capacity in younger individuals and seasonal migrants (Cinner et al. 2015). Identifying such vulnerabilities within a community requires an understanding of local assets and value structures (O'Brien and Wolf 2010). Thus, higher resolution assessments are needed to identify different sets of variables that define vulnerability within a given context. Furthermore, many proposed adaptation responses operate at the scale of an individual resource user (e.g., livelihood diversification, knowledge sharing, personal financial planning). In oyster fishing communities such as those in coastal Louisiana, as with other resource-dependent communities, the expectation is that individuals are vulnerable to environmental hazards in disparate ways, and that these differences could translate to differences in receptiveness and success with regard to proposed adaptation strategies.

Vulnerability research specific to communities that are dependent on oysters as a fishery resource is scant (but see Ekstrom et al. 2015), and, to our knowledge, no studies have examined sources of vulnerability across different occupational roles or use primary data. Thus, there is a lack of data that link resource users and their different roles in oyster fisheries to environmental change brought about by hazards. Closing this gap will inform context-appropriate allocation of adaptation resources, a particular concern of management agencies in Louisiana and other Gulf Coast states. Our case study works to fill this gap and establish a better understanding of how indicators of susceptibility and adaptive capacity (as metrics of vulnerability) are interacting across the oyster fishing industry in Louisiana. We use interviews among three unique occupational roles in the oyster fishery to determine what factors contribute to overall vulnerability.

\section{Study site and context}

Terrebonne Parish is at the heart of coastal Louisiana (Fig. 1). The parish seat is located in Houma and has a population of 112,086 (U.S. Census Bureau 2011). The land area is $3191 \mathrm{~km}^{2}$, making it the second largest parish in Louisiana. Its most distinctive feature is the long coastline with extensive marsh habitat, which encompasses approximately $2201 \mathrm{~km}^{2}$, or $41 \%$ of its total area. This marsh habitat ranges considerably from inland fresh marsh 
to brackish and saline salt marsh near the bays and the gulf. This makes it one of the largest and most diverse ecological basins within Louisiana. Thus, the history of Terrebonne Parish is tightly linked with coastal activities. In fact, these activities account for $>20 \%$ of Louisiana's current seafood production, much of it coming from the oyster and shrimp fisheries (Ogunyinka et al. 2011). Unemployment is low in the parish and the oil and gas industry and fisheries employ the majority of the population. Despite this, nearly $20 \%$ of the population in Terrebonne Parish lives below the poverty line (U.S. Census Bureau 2011).

Coastal land loss and erosion plague Terrebonne Parish. Between 1956 and 2005, > $876 \mathrm{~km}^{2}$ of land was converted from wetlands to large open water bodies primarily because of subsidence and hurricanes (Barras 2006). The parish has the highest subsidence rates on the coast, with values ranging from $10.7 \mathrm{~mm} / \mathrm{yr}$ to as high as $20 \mathrm{~mm} / \mathrm{yr}$ (Penland 1990). Even though Terrebonne Parish experiences the highest rate of land loss in Louisiana, it is without a functional hurricane protection system. The lack of protection makes the area especially susceptible to rapid environmental change, as predictions indicate that hurricanes will increase in frequency and magnitude due to climate change (Knutson et al. 2010).

Important to the context of our study is the fact that the Louisiana oyster fishery is managed using a fixed lease system. Fishers harvest oysters from both public oyster grounds and from water bottoms leased by private entities. There is approximately 6880 $\mathrm{km}^{2}$ available for public harvest in Louisiana, and approximately $1619 \mathrm{~km}^{2}$ currently under private lease (LDWF 2018). Although there is much less land under private lease than public, $89 \%$ of all harvested oysters came from private leases in 2017 (LDWF 2018). The private leases are owned by individuals and are long term with fixed locations. Terrebonne Parish has 2246 oyster leases registered with the state, totaling $28 \%$ of all leases within Louisiana. This amount encompasses $388 \mathrm{~km}^{2}$ of oyster leases (LDWF 2018). These attributes make the fishery and the lease owners more susceptible to hazardous environmental conditions than aquaculture or a shifting water bottom lease system or finfish fisheries. In Terrebonne Parish and throughout coastal Louisiana, there are individuals who represent a variety of roles in the oyster fishery, from the fishers to lease owners and distributors. Some individuals occupy multiple roles simultaneously.

The high dependency of Terrebonne Parish's citizens on the oyster fishery, coupled with its land loss and susceptibility to hurricanes, make it a good location for our research but also provides limitations for how much the results can be extrapolated. For example, the west side of Terrebonne Parish (Terrebonne basin) is very ecologically different for oyster habitat than the eastern side (Timbalier subbasin) because of the salinity and sediment regimes (Melancon et al. 1998). Additionally, there are plans to construct a large freshwater diversion in the Parish (Atchafalaya River Sediment Diversion) as part of the State of Louisiana's 2017 Coastal Master Plan. This plan will rapidly change the environmental conditions of Terrebonne Parish's salt marsh and, thus, oyster habitat and leases. Agencies such as Louisiana's Coastal Protection and Restoration Agency, working with Louisiana Sea Grant, would benefit from research that proactively identifies the most vulnerable individuals.

\section{METHODS}

\section{Survey design}

We designed a survey to describe the relationship of an individual to oysters and the oyster fishery. This survey was intended to determine an individual's level of susceptibility and adaptive capacity to hazards that result in environmental changes in oyster habitat. We did not include indicators of exposure because all individuals in our survey location were known to fish within the same estuarine ecosystem; it was reasonable to assume that they are equally exposed to environmental hazards. In other words, the fine spatial scale of our investigation allowed us to focus on susceptibility and adaptive capacity, attributes that may respond differentially to rapid environmental change. For this process, we developed 11 indicators of susceptibility and 5 indicators of adaptive capacity from a literature review of previous vulnerability studies that are most likely to capture the properties of interest. We also consulted with local state extension agents who work directly with the oyster industry and managers (Table 1). The indicators of susceptibility only included livelihood susceptibility because fishing gear is homogenous across the oyster fishery in Louisiana because everyone uses the same method (dredge). Thus, the susceptibility indicators focused on how much people depend on oysters, how many linkages they have to other economic sectors, and the directionality of those linkages. The adaptive capacity indicators focused on an ability to plan, one's flexibility, and risk perception.

Most of the structured questions were designed to elicit an attitude, opinion, or stance. For example, respondents were asked to rate how strongly they agreed or disagreed with a statement using a 10-point Likert scale, where $1=$ very strongly disagree and $10=$ very strongly agree. Other structured questions were designed to elicit a definitive yes or no answer. An initial version of the survey was tested over the telephone with three randomly selected individuals within the industry to ensure that the questions were clear and understandable. Those individuals were not included in the survey implementation.

\section{Survey administration}

Surveys (Appendix 1) were administered to participants in Terrebonne Parish between February and May 2014. Ethical permission was obtained from Louisiana State University's Institutional Review Board (\#E8633), and informed consent was obtained from participants before conducting surveys. Key informants were identified using a snowball approach initiated using local knowledge of the fishery and its participants. Ultimately, the survey was administered to 21 individuals $(91 \%$ response rate), and interviews took between 50 and $100 \mathrm{~min}$ to complete. Each individual was classified based on their occupation as either an operator (fisher only; $N=9$ ), owner/ operator (fisher who also owned the oyster lease; $N=5$ ), or owner (nonfisher who owned the oyster lease; $N=7$ ).

\section{Data analysis}

We bounded each indicator of susceptibility and adaptive capacity so that it ranged from 0 to 1 . This scaling is important because many of the raw indicators were on different scales (binomial or continuous) with different units. By bounding each indicator from 0 to 1 , the data can be combined to develop a metric of susceptibility and adaptive capacity for each individual. 
Table 1. Indicators of susceptibility and adaptive capacity used for our study, including the minimum and maximum (continuous) values reported from the dataset used for bounding.

\begin{tabular}{|c|c|c|c|}
\hline Indicator & Metric & Description & $\begin{array}{l}\text { Bounds (minimum, } \\
\text { maximum) }\end{array}$ \\
\hline Access & Susceptibility & Perceptions of equity & 5,10 \\
\hline Motivation to change & Susceptibility & Strength of belief in an action & 1,10 \\
\hline Norms & Susceptibility & Responsibility in resource actions & 3,10 \\
\hline Occupational identity & Susceptibility & Awareness of oneself in relation to job & 1,10 \\
\hline Perceptions of environment & Susceptibility & Ways of understanding the environment & 2,10 \\
\hline Perceptions of management & Susceptibility & Belief in efficacy of rules and regulations & 1,10 \\
\hline Personal attachment & Susceptibility & Attachment to place, community, and fishery & 1,10 \\
\hline Personal identity & Susceptibility & Study area and occupation as part of the concept of oneself & 2,9 \\
\hline Stewardship & Susceptibility & Responsible use and protection of the environment & 2,8 \\
\hline Values & Susceptibility & Expression of one's motivational goals & 1,9 \\
\hline Well-being & Susceptibility & $\begin{array}{l}\text { State of being with others and environment that arises when } \\
\text { human needs are met }\end{array}$ & 2,8 \\
\hline Buffers & Adaptive capacity & Psychological and financial preparation & 1,10 \\
\hline Interest in adapting & Adaptive capacity & Concern with gaining knowledge on preparing for change & 4,10 \\
\hline Planning & Adaptive capacity & Degree of shared learning, experimenting, and reorganizing & 1,10 \\
\hline Risk perception & Adaptive capacity & One's level of confidence in how change will affect the ecosystem & 2,10 \\
\hline Trust & Adaptive capacity & $\begin{array}{l}\text { Level of trust in community members, local leaders, government } \\
\text { officials, scientists, media }\end{array}$ & 1,10 \\
\hline
\end{tabular}

Not all indicators of susceptibility and adaptive capacity have the same level of importance; therefore, we weighted each indicator using principal components analysis (PCA) based on a covariance matrix (McClanahan et al. 2012, Cinner et al. 2015). It was out of the scope of our study to conduct an expert workshop to determine relative indicator weightings (McClanahan et al. 2012). Specifically, we derived a factor score using a weighted mean for the set of statements describing each indicator of susceptibility and adaptive capacity based on its contribution to each principal component. To do this, we calculated each weight $W$ as:

$$
\mathrm{W}=\sum_{k=1}^{G} E_{j} F_{i j}
$$

where $i$ is the indicator, $k$ is the principal component, $G$ is the number of principal components determined by the proportion of variation explained, $E_{\mathrm{j}}$ is the eigenvalue of principal component $k$, and $F_{\mathrm{ij}}$ is the factor loading of indicator $i$ on principal component $k$. The weights were all normalized so that the sum of all the weights (11 indicators for susceptibility or 5 indicators for adaptive capacity) equaled 1. The normalized weights were then used to calculate the weighted susceptibility or adaptive capacity index $D$ for each occupational role as:

$$
\mathrm{D}=\sum_{i=1}^{G} n W_{i} v_{i}
$$

where $i$ is the indicator, $G$ is the number of indicators, $n W_{\mathrm{i}}$ is the normalized weight of indicator $i$, and $V_{\mathrm{i}}$ is the normalized value of indicator $i$. Finally, the vulnerability $V$ of each occupational role to environmental change was calculated as the difference between the susceptibility score with the coping and adaptive capacity score (IPCC 2012, 2014, Hagenlocher et al. 2018). Because we assume all individuals in this study have a constant exposure term $(E)$, this term was removed from the calculations.
We also examined the data after they were bounded to ensure there was variation to reflect differential contributions to susceptibility and adaptive capacity scores.

To test whether factor scores differed among participant groups (operator, owner, and owner/operator), we used one-way analysis of variance followed by individual contrasts with an alpha level of 0.05 as the minimum level to test the significance of each relationship. We used Pearson correlation to examine the relationship between indicators of susceptibility and adaptive capacity.

\section{RESULTS}

\section{Susceptibility}

The three user groups displayed considerable variation in many of the susceptibility indicators (Table 2). In particular, motivation to change, occupational identity, stewardship, and values differed significantly among resource user groups, and owner/operators were the most sensitive to hazards affecting oyster habitat. Operators had the lowest values for all of the susceptibility indicators, which is reflected in questions such as those addressing motivation to change. None of the operators believed that they could make a difference or influence the resilience of the local oyster habitat and the environment, whereas many of the owner/ operators did. Owners often had scores in between those of the other two groups, and their overall susceptibility factor score reflected that. Several indicators did not vary significantly across the user groups such as access, norms, perceptions of the environment and management, personal attachment and identity, and well-being.

The PCA of susceptibility indicators revealed that the first two axes explained $57 \%$ of the variance (Fig. S1 in Appendix 2). Access, motivation to change, occupational identity, perceptions of the environment, stewardship, values, and well-being all had considerable factor loadings on the first principal component axis (Table S1 in Appendix 2). Three indicators loaded negatively on 
this axis, and those were also the same three that had the greatest normalized weight, which were access, occupational identity, and well-being (Table S2 in Appendix 2). On the second axis, occupational identity, access, perceptions of management, and well-being all loaded substantially, with access and well-being loading negatively. Norms, personal attachment, and personal identity did not load on any axis, primarily because there was little variance in the scores.

Table 2. Livelihood susceptibility factor scores for each indicator by occupation. A total score of 1 would mean that all respondents depended on the oyster fishery, whereas a total score of 0 would mean that none of the respondents depended on the oyster fishery for their livelihoods. Different letters represent significant differences between occupations within an indicator.

\begin{tabular}{lccc}
\hline \hline Susceptibility indicator & Owner & Operator & $\begin{array}{c}\text { Owner/ } \\
\text { operator }\end{array}$ \\
\hline Access & 0.102 & 0.131 & 0.150 \\
Motivation to change*** & $0.048^{\mathrm{ab}}$ & $0.022^{\mathrm{a}}$ & $0.064^{\mathrm{b}}$ \\
Norms & 0.017 & 0.012 & 0.020 \\
Occupational identity** & $0.093^{\mathrm{a}}$ & $0.052^{\mathrm{b}}$ & $0.103^{\mathrm{a}}$ \\
Perceptions of environment & 0.046 & 0.031 & 0.074 \\
Perceptions of management & 0.035 & 0.044 & 0.064 \\
Personal attachment & 0.018 & 0.012 & 0.017 \\
Personal identity & 0.036 & 0.034 & 0.042 \\
Stewardship** & $0.054^{\mathrm{a}}$ & $0.022^{\mathrm{b}}$ & $0.045^{\mathrm{a}}$ \\
Values* & $0.057^{\mathrm{a}}$ & $0.018^{\mathrm{b}}$ & $0.053^{\mathrm{a}}$ \\
Well-being & 0.181 & 0.162 & 0.195 \\
Total & $0.688^{\mathrm{ab}}$ & $0.539^{\mathrm{a}}$ & $0.827^{\mathrm{b}}$ \\
\hline
\end{tabular}

$* P<0.05,{ }^{* *} P<0.01,{ }^{* * *} P<0.001$

\section{Adaptive capacity}

The adaptive capacity indicators showed individual variability among the resource user groups, but overall, they were not significantly different from one another (Table 3). Buffers and trust were greatest for owner/operators, whereas planning was greatest for owners. Operators had the lowest scores for all three of these indicators. Interest in adapting and risk perception did not vary significantly across groups.

Table 3. Adaptive capacity factor scores for each indicator by occupation. A total score of 1 would mean that respondents have the ability to recover from changes in the oyster fishery, whereas a total score of 0 would mean that none of the respondents could recover. Different letters represent significant differences between occupations within an indicator.

\begin{tabular}{lccc}
\hline \hline Adaptive capacity indicator & Owner & Operator & $\begin{array}{c}\text { Owner/ } \\
\text { operator }\end{array}$ \\
\hline Buffers* & $0.058^{\mathrm{ab}}$ & $0.030^{\mathrm{a}}$ & $0.081^{\mathrm{b}}$ \\
Interest in adapting & 0.179 & 0.154 & 0.251 \\
Planning* & $0.116^{\mathrm{b}}$ & $0.028^{\mathrm{a}}$ & $0.083^{\mathrm{ab}}$ \\
Risk perception & 0.140 & 0.127 & 0.146 \\
Trust* & $0.082^{\mathrm{ab}}$ & $0.061^{\mathrm{a}}$ & $0.100^{\mathrm{b}}$ \\
Total & 0.575 & 0.401 & 0.661 \\
$* P<0.05, * * P<0.01, * * * P<0.001$. & & \\
\end{tabular}

The first two axes from the PCA of adaptive capacity indicators accounted for $91 \%$ of the variance (Figure S2 in Appendix 2).
The first principal component axis was influenced by planning, buffers, trust, and interest in adapting (Table S3 in Appendix 2). Of these variables, planning and buffers loaded negatively on the axis, whereas interest in adapting and trust loaded positively. Risk perception did not load substantially on the first axis but did on the second axis (negatively) along with interest in adapting. The indicators with the greatest normalized weights were interest in adapting, planning, and risk perception (Table S4 in Appendix 2).

\section{Vulnerability}

Our measure of vulnerability consisted of two components: (livelihood) susceptibility and adaptive capacity. There were some significant relationships between indicators of components (Table 4). Oyster resource users that had higher adaptive capacity scores also had higher levels of motivation to change, norms, perceptions of the environment and management, stewardship, values, and well-being. In other words, the resource users most vulnerable to changes in oyster habitat will be those with low levels of the above susceptibility attributes. Risk perception was only correlated with well-being, whereas buffers, interest in adapting, and trust were correlated with four different susceptibility indicators. Access, occupational identity, and personal attachment and identity were not correlated with any indicators of adaptive capacity.

Table 4. Pearson correlations between dimensions of susceptibility and adaptive capacity.

\begin{tabular}{|c|c|c|c|c|c|}
\hline \multirow[b]{2}{*}{$\begin{array}{l}\text { Susceptibility } \\
\text { indicator }\end{array}$} & \multicolumn{5}{|c|}{ Adaptive capacity indicator } \\
\hline & Buffers & $\begin{array}{c}\text { Interest in } \\
\text { adapting }\end{array}$ & Planning & $\begin{array}{c}\text { Risk } \\
\text { percept- } \\
\text { ion }\end{array}$ & Trust \\
\hline Access & -0.012 & 0.149 & -0.19 & 0.032 & -0.034 \\
\hline Motivation to change & $0.543^{*}$ & $0.512 *$ & 0.405 & -0.007 & $0.722 * * *$ \\
\hline Norms & 0.416 & $0.453^{*}$ & 0.241 & -0.245 & $0.571 * *$ \\
\hline Occupational identity & 0.377 & 0.196 & 0.330 & 0.138 & 0.351 \\
\hline $\begin{array}{l}\text { Perceptions of } \\
\text { environment }\end{array}$ & $0.463^{*}$ & $0.527^{*}$ & 0.411 & -0.256 & $0.713^{* * *}$ \\
\hline $\begin{array}{l}\text { Perceptions of } \\
\text { management }\end{array}$ & $0.465^{*}$ & 0.357 & 0.166 & -0.015 & 0.366 \\
\hline Personal attachment & 0.040 & 0.272 & 0.368 & 0.033 & 0.214 \\
\hline Personal identity & -0.002 & 0.365 & 0.176 & -0.055 & 0.200 \\
\hline Stewardship & 0.419 & $0.466^{*}$ & $0.578 * *$ & -0.058 & $0.495^{*}$ \\
\hline Values & $0.653^{* *}$ & 0.219 & $0.633^{* *}$ & 0.043 & 0.373 \\
\hline Well-being & -0.146 & -0.156 & -0.148 & $0.441^{*}$ & 0.049 \\
\hline
\end{tabular}

Oyster resource users varied in their overall vulnerability to changes in oyster habitat (Fig. 2). Individuals who were owner/ operators were the most sensitive to these hazards but had the greatest ability to respond to and recover from change. The opposite was true for operators, who had the lowest scores for susceptibility and adaptive capacity. Between these groups were owners, who had a moderate level of susceptibility due to their values and perceptions of the environment, as well as a moderate level of adaptive capacity.

\section{DISCUSSION}

Vulnerability to environmental hazards is a problem for resource users working at all levels within Terrebonne Parish's oyster fishery, but the mechanisms were unique to the occupation. 
Table 5. Possible management and policy responses to influence different types of social vulnerability for the Louisiana oyster fishery. Potential to influence vulnerability is derived from the factor scores.

\begin{tabular}{|c|c|c|c|}
\hline Metric & $\begin{array}{l}\text { Vulnerability } \\
\text { component }\end{array}$ & $\begin{array}{l}\text { Potential to } \\
\text { influence } \\
\text { vulnerability }\end{array}$ & Possible policy or management actions for enhancement \\
\hline \multirow[t]{11}{*}{ Susceptibility } & Access & Low & Participation in permit regulations and distribution \\
\hline & Motivation to change & High & Education and participation in ecological research \\
\hline & Norms & Medium & Support for community initiatives and organizations to improve environment \\
\hline & Occupational identity & Low & Develop supplemental employment options via support for economic growth \\
\hline & $\begin{array}{l}\text { Perceptions of } \\
\text { environment }\end{array}$ & High & Improved communication of research \\
\hline & $\begin{array}{l}\text { Perceptions of } \\
\text { management }\end{array}$ & Medium & Improved communication between policy makers and resource users \\
\hline & Personal attachment & Low & Cultural awareness education \\
\hline & Personal identity & Low & Develop supplemental livelihood activities \\
\hline & Stewardship & High & Encourage partnerships between research organizations and resource users \\
\hline & Values & High & Promote creation and expression of place \\
\hline & Well-being & Medium & Support for economic growth \\
\hline \multirow[t]{5}{*}{ Adaptive capacity } & Buffers & High & $\begin{array}{l}\text { Capacity building on how to reduce and spread financial and social risk, including } \\
\text { encouraging alternative oyster fishery approaches and off-bottom aquaculture }\end{array}$ \\
\hline & Interest in adapting & Medium & Education and participation in regulations \\
\hline & Planning & Medium & Outreach on potential impacts of environment to changes in income \\
\hline & Risk perception & Low & Poverty alleviation plans and pro-poor growth policies \\
\hline & Trust & High & Promote transparency and increase communication among multiple stakeholders \\
\hline
\end{tabular}

Fig. 2. Susceptibility plotted against adaptive capacity factor scores. Note that the adaptive capacity axis is flipped. The arrow highlights less vulnerable to more vulnerable stakeholder groups, as do the quadrat colors. Green = least vulnerable, red $=$ most vulnerable, yellow $=$ moderately vulnerable but for different reasons (either low adaptive capacity or high susceptibility).

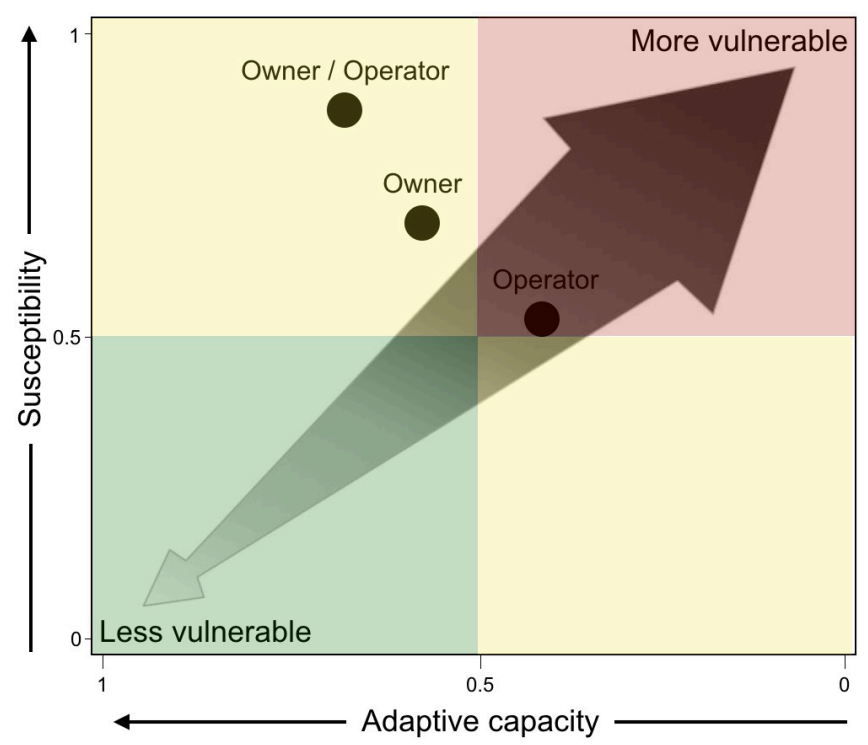

Owners of oyster leases were highly sensitive to potential changes in the viability of the oyster fishery, which was largely due to resource dependency and strong personal connections to the coastal environment where they work. These same individuals, however, had some ability to cope with and respond to disturbance via financial buffers and through trusted sources of information regarding the state of the fishery. Oyster fishers who did not own any portion of a lease exhibited the inverse vulnerability profile. These operators did not feel as personally connected to the profession as did lease owners, but were still vulnerable to environmental hazards because of a substantially reduced capacity to adapt.

Policy and management responses that aim to reduce overall vulnerability can work either by decreasing susceptibility or enhancing adaptive capacity (Ekstrom et al. 2015). To maximize the potential for success, interventions targeting those indicators that strongly influence overall vulnerability may be most successful. By examining indicator factor scores, it became clear where interventions would be expected to have the greatest effect in the study system (Table 5). For example, susceptibility was heightened by environmental stewardship and values, and was reduced when an individual was motivated to alter behaviors to improve the health of oysters. Therefore, a policy action that provides information on threats to Terrebonne Parish oysters and engages resource users in best practices for the industry can address a need to increase the motivation to change. Another potential policy avenue to reduce the susceptibility of resource users in the oyster fishery could be to include these stakeholders in research activities and communication of research, thereby encouraging partnerships between research organizations and resource users. Such collaborative actions can lead to comanagement of resources, which has positive effects across both ecological and social dimensions in resource-dependent communities (Sen and Nielsen 1996, Mackinson et al. 2011, Cinner and Huchery 2014). They have also been shown to give individuals a stronger sense of ownership and agency in their ability to influence the environment positively (see review by 
Stringer et al. 2006). Future work in the oyster industry would benefit from better inclusion of stakeholders in the development of indicators and project development (Moser and Ekstrom 2011).

Given that impacts of a changing climate are already being felt in many resource-dependent communities, there is a particular need to bolster the adaptive capacity of individuals (Cinner et al. 2018). Among the oyster resource users in our study, high adaptive capacity was characterized by financial security or planning ("buffers") and a high level of trust placed in personal sources of information regarding the state of the local oyster fishery. Interventions to enhance these aspects of adaptive capacity include the provision of resources such as workshops that focus on how to reduce and dilute risk, as well as facilitation of the flow of information among resource users and other relevant stakeholders such as management entities and academic research institutions. The first step in such interventions would require a social network analysis that identifies the information conduits and nodes within the fishery (Markantonatou et al. 2016). Other studies have found social network structures that suggest high potential for social capital based on low fragmentation (in a Kenyan fishing community; Bodin and Crona 2008) or high density (in a UK lobster fishery; Turner et al. 2014). Network density, or the total number of links between actors in the system, and network modularity, the extent of separate internally dense groups, are important factors in trust (Bodin et al. 2006). Increasing density and decreasing modularity within the Terrebonne Parish oyster fishery network would likely increase feelings of belonging and group cohesion (bolstering trust), as well as improve information flow among stakeholders.

Associations between the vulnerability indicators suggest that targeting particular aspects of susceptibility and adaptive capacity may also have beneficial ripple effects for resource users. For example, among our respondents, an increase in trust was correlated with stronger motivation to change environmental behaviors. Citizen science initiatives could be a potential avenue to influence trust, creating a platform for increased transparency and data sharing, as well as promoting active engagement in policy making (Macnaghten and Jacobs 1997). Furthermore, stronger motivation toward behavior change in the respondents correlated with better financial planning and interest in preparing for major hazards affecting the oyster industry (e.g., oil spills). This finding is supported by studies in which individuals perceive being financially equipped to respond to change as a major component of their adaptation to environmental disturbance (Marshall and Marshall 2007, Marshall 2010). The fact that some of the strongest indicators of vulnerability in our study were correlated suggests that decreased vulnerability results from interventions that are highly linked, so that an initial adjustment may ultimately act as a trigger for significantly improved outcomes.

The particular nature of the oyster fishery within Terrebonne Parish serves as a point of discussion and potential caveat to extrapolating our research findings. Resource extraction within the fishery has attributes reminiscent of aquaculture systems or a spatial privatization where exclusive rights are granted to a license or lease holder. Here, fishers may harvest juvenile oysters from public grounds and leased oyster seed sites, then leave them for a period of 2-6 months before harvest. This process is very different from other (e.g., finfish) fisheries, in which capture is not predicated on stocking juveniles within the system and spatial privatization (with the exception of some management policies such as territorial user rights fisheries). Therefore, we regard vulnerability profiles of resource users within the Terrebonne Parish oyster fishery system as unique to those within other capture fishery seascapes. This is a key point when considering why the stakeholders in our study responded differentially. Lastly, there have been developments within the oyster industry since our study took place in 2014, which may influence adaptation strategies and attitudes differently today.

Generalization of our findings is also limited by a relatively small sample size. Although we captured approximately $10 \%$ of the stakeholders in Terrebonne Parish's oyster fishery, the lease owners and oyster fishers/lease owners represented a much higher percentage of the fishery market share. When considering this distribution, our survey respondents fished or owned the rights to fish on approximately $65 \%$ of the harvestable area in Terrebonne Parish. Capturing information from more individuals within the fishery but across different parishes in Louisiana would help to better identify useful broad-scale management interventions. Lastly, given that our survey was administered within a single region, the vulnerability profiles and relationships between indicators shown here should not be extrapolated to oyster resource-dependent individuals in other locations or systems. Our findings will hopefully serve as a platform from which to characterize vulnerability further within the context of a climate-threatened industry. Future studies could aim to test the relationships and findings presented here through assessment of other oyster fishing communities facing similar adaptation challenges.

One question regarding vulnerability assessments that was not addressed explicitly by our study is whether or not indicators of susceptibility or adaptive capacity should contribute differentially to overall vulnerability scores. In other words, we did not consider whether there are circumstances in which some indicators should be weighted more strongly than others a priori based on perceived impact (McClanahan et al. 2012). For instance, oyster fishers (operators) in Terrebonne Parish do not identify with their occupation very strongly and are not tied to the industry by lease ownership. Occupational multiplicity (i.e., diversification) can act as a financial buffer for individuals employed in resourcedependent sectors threatened by uncertainty (Allison and Ellis 2001). If operators are able to switch jobs and income streams easily in response to a change in the oyster fishery, this indicator (occupational identity) may constitute a disproportionate decrease in their susceptibility that is not currently captured in our study. Incorporating situational responses to environmental hazards was not in the scope of our study. Previous vulnerability assessments of resource-dependent communities have weighted indicators of exposure by the amount of scientific evidence available to support the impact (Cinner et al. 2013). Future studies could aim to test how indicators of social susceptibility and adaptive capacity might be weighted to capture their influence on overall vulnerability more accurately and compare them with weightings derived from statistical techniques such as the one we used.

Our assessment of vulnerability among oyster resource users in coastal Louisiana focused on the social factors that mediate an individual's response to environmental hazards. We recognize, 
however, that the components defining vulnerability (i.e., exposure, susceptibility, and adaptive capacity) are influenced by ecological factors as well. In the study system, ecological vulnerability is exemplified by variation in oyster populations to environmental hazards based on age or disease resistance (Han et al. 2007). The literature on vulnerability over the last decade has in fact moved toward a multidisciplinary approach using a social-ecological framework (Perry et al. 2011, Kittinger et al. 2013, Bennett et al. 2016, Sebesvari et al. 2016). The central idea is that humans affect ecological dynamics, and vice versa, such that separating the two systems misses a major driver of structure and functioning, both in ecosystems and societies. One way to explicitly link both social and ecological processes is via the framework (IPCC 2012, 2014) that we use in our study and using primary survey data. This application allowed us to assess both the susceptibility and adaptive capacity of the Terrebonne Parish oyster fishery system and differentiate how indicators change among stakeholders. An alternative methodology might be to use a systems network approach to integrate ecological and social factors across all components of vulnerability (Debortoli et al. 2018). Whatever the approach, maximizing the adaptation of oyster-dependent communities to environmental change will require that biophysical and ecological variability be considered in vulnerability assessments and hazard risk management.

\section{CONCLUSION}

Vulnerability assessments that evaluate susceptibility and adaptive capacity of resource-dependent communities are useful to determine policy relevance and leverage points for management. Our application in the oyster fishery of Terrebonne Parish, Louisiana, revealed differences in the magnitude and direction of key sources of vulnerability to environmental hazards for fishers, lease owners, and individuals who occupied both roles. While lease owners and owner/operators were the most susceptible to hazards because of strong occupational identities and values, they were also more adaptable. This adaptability offset their overall vulnerability, whereas oyster fishers were not as well positioned to adapt to change because of low levels of trust. Proactively identifying those individuals who are most vulnerable to environmental hazards is critical for identifying and prioritizing strategies for building social resilience.

Responses to this article can be read online at: http://www.ecologyandsociety.org/issues/responses. php/11101

\section{Acknowledgments:}

We acknowledge funding from Louisiana State University's Coastal Sustainability Studio Small Projects Fund. We are grateful to the oyster industry individuals who participated in this study and $P$. Carvalho for assistance with the map. The use of trade, product, industry, or firm names or products is for informative purposes only and does not constitute an endorsement by the U.S. Government or the U.S. Geological Survey.

\section{LITERATURE CITED}

Adger, W. N. 1999. Social vulnerability to climate change and extremes in coastal Vietnam. World Development 27(2):249-269. https://doi.org/10.1016/S0305-750X(98)00136-3

Allison, E. H., and F. Ellis. 2001. The livelihoods approach and management of small-scale fisheries. Marine Policy 25 (5):377-388. https://doi.org/10.1016/S0308-597X(01)00023-9

Allison, E. H., A. L. Perry, M.-C. Badjeck, W. N. Adger, K. Brown, D. Conway, A. S. Halls, G. M. Pilling, J. D. Reynolds, N. L. Andrew, and N. K. Dulvy. 2009. Vulnerability of national economies to the impacts of climate change on fisheries. Fish and Fisheries 10(2):173-196. https://doi.org/10.1111/j.1467-2979.2008.00310. $\underline{\mathrm{X}}$

Barras, J. A. 2006. Land area changes in coastal Louisiana after the 2005 hurricanes: a series of three maps. Open-file Report 2006-1274. U.S. Geological Survey, Reston, Virginia, USA. https://doi.org/10.3133/ofr20061274

Beck, M. W., R. D. Brumbaugh, L. Airoldi, A. Carranza, L. D. Coen, C. Crawford, O. Defeo, G. J. Edgar, B. Hancock, M. C. Kay, H. S. Lenihan, M. W. Luckenbach, C. L. Toropova, G. Zhang, and X. Guo. 2011. Oyster reefs at risk and recommendations for conservation, restoration, and management. Bioscience 61(2):107-116. https://doi.org/10.1525/bio.2011.61.2.5

Bennett, N. J., J. Blythe, S. Tyler, and N. C. Ban. 2016. Communities and change in the anthropocene: understanding social-ecological vulnerability and planning adaptations to multiple interacting exposures. Regional Environmental Change 16(4):907-926. https://doi.org/10.1007/s10113-015-0839-5

Birkmann, J., O. D. Cardona, M. L. Carreño, A. H. Barbat, M. Pelling, S. Schneiderbauer, S. Kienberger, M. Keiler, D. Alexander, P. Zeil, and T. Welle. 2013. Framing vulnerability, risk and societal responses: the MOVE framework. Natural Hazards 67(2):193-211. https://doi.org/10.1007/s11069-013-0558-5

Bodin, Ö., and B. I. Crona. 2008. Management of natural resources at the community level: exploring the role of social capital and leadership in a rural fishing community. World Development 36(12):2763-2779. https://doi.org/10.1016/j. worlddev.2007.12.002

Bodin, Ö., B. Crona, and H. Ernstson. 2006. Social networks in natural resource management: What is there to learn from a structural perspective? Ecology and Society 11(2):r2. [online] URL: http://www.ecologyandsociety.org/vol11/iss2/resp2/

Cheung, W. W. L., V. W. Y. Lam, J. L. Sarmiento, K. Kearney, R. Watson, D. Zeller, and D. Pauly. 2010. Large-scale redistribution of maximum fisheries catch potential in the global ocean under climate change. Global Change Biology 16(1):24-35. https://doi. org/10.1111/j.1365-2486.2009.01995.X

Cinner, J. E., W. N. Adger, E. H. Allison, M. L. Barnes, K. Brown, P. J. Cohen, S. Gelcich, C. C. Hicks, T. P. Hughes, J. Lau, N. A. Marshall, an T. H. Morrison. 2018. Building adaptive capacity to climate change in tropical coastal communities. Nature Climate Change 8(2):117-123. https://doi.org/10.1038/s41558-017-0065-x

Cinner, J., and C. Huchery. 2014. A comparison of social outcomes associated with different fisheries co-management 
institutions. Conservation Letters 7(3):224-232. https://doi. org/10.1111/conl.12057

Cinner, J. E., C. Huchery, E. S. Darling, A. T. Humphries, N. A. J. Graham, C. C. Hicks, N. Marshall, and T. R. McClanahan. 2013. Evaluating social and ecological vulnerability of coral reef fisheries to climate change. Plos One 8(9):e74321. https://doi. org/10.1371/journal.pone.0074321

Cinner, J. E., C. Huchery, C. C. Hicks, T. M. Daw, N. Marshall, A. Wamukota, and E. H. Allison. 2015. Changes in adaptive capacity of Kenyan fishing communities. Nature Climate Change 5(9):872-876. https://doi.org/10.1038/nclimate2690

Cinner, J. E., T. R. McClanahan, N. A. J. Graham, T. M. Daw, J. Maina, S. M. Stead, A. Wamukota, K. Brown, and Ö. Bodin. 2012. Vulnerability of coastal communities to key impacts of climate change on coral reef fisheries. Global Environmental Change 22(1):12-20. https://doi.org/10.1016/j.gloenvcha.2011.09.018

Coen, L. D., R. D. Brumbaugh, D. Bushek, R. Grizzle, M. W. Luckenbach, M. H. Posey, S. P. Powers, and S. G. Tolley. 2007. Ecosystem services related to oyster restoration. Marine Ecology Progress Series 341:303-307. https://doi.org/10.3354/meps341303

Debortoli, N. S., J. S. Sayles, D. G. Clark, and J. D. Ford. 2018. A systems network approach for climate change vulnerability assessment. Environmental Research Letters 13(10):104019. https://doi.org/10.1088/1748-9326/aae24a

Eakin, H., and A. L. Luers. 2006. Assessing the vulnerability of social-environmental systems. Annual Review of Environment and Resources 31:365-394. https://doi.org/10.1146/annurev. energy.30.050504.144352

Ekstrom, J. A., L. Suatoni, S. R. Cooley, L. H. Pendleton, G. G. Waldbusser, J. E. Cinner, J. Ritter, C. Langdon, R. van Hooidonk, D. Gledhill, K. Wellman, M. W. Beck, L. M. Brander, D. Rittschof, C. Doherty, P. E. T. Edwards, and R. Portela. 2015. Vulnerability and adaptation of US shellfisheries to ocean acidification. Nature Climate Change 5(3):207-214. https://doi. org/10.1038/nclimate2508

Emrich, C. T., and S. L. Cutter. 2011. Social vulnerability to climate-sensitive hazards in the southern United States. Weather, Climate, and Society 3(3):193-208. https://doi.org/10.1175/2011WCAS1092.1

Frazier, T. G., C. M. Thompson, and R. J. Dezzani. 2014. A framework for the development of the SERV model: a Spatially Explicit Resilience-Vulnerability model. Applied Geography 51:158-172. https://doi.org/10.1016/j.apgeog.2014.04.004

Frigerio, I., and M. De Amicis. 2016. Mapping social vulnerability to natural hazards in Italy: a suitable tool for risk mitigation strategies. Environmental Science and Policy 63:187-196. https:// doi.org/10.1016/j.envsci.2016.06.001

Hagenlocher, M., F. G. Renaud, S. Haas, and Z. Sebesvari. 2018. Vulnerability and risk of deltaic social-ecological systems exposed to multiple hazards. Science of the Total Environment 631-632:71-80. https://doi.org/10.1016/j.scitotenv.2018.03.013

Han, F., R. D. Walker, M. E. Janes, W. Prinyawiwatkul, and B. Ge. 2007. Antimicrobial susceptibilities of Vibrio parahaemolyticus and Vibrio vulnificus isolates from Louisiana Gulf and retail raw oysters. Applied and Environmental Microbiology 73(21):7096-7098. https://doi.org/10.1128/AEM.01116-07

Hughes, S., A. Yau, L. Max, N. Petrovic, F. Davenport, M. Marshall, T. R. McClanahan, E. H. Allison, and J. E. Cinner. 2012. A framework to assess national level vulnerability from the perspective of food security: the case of coral reef fisheries. Environmental Science and Policy 23:95-108. https://doi. org/10.1016/j.envsci.2012.07.012

Intergovernmental Panel on Climate Change (IPCC). 2012. Managing the risks of extreme events and disasters to advance climate change adaptation. C. B. Field, V. Barros, T. F. Stocker, D. Qin, D. J. Dokken, K. L. Ebi, M. D. Mastrandrea, K. J. Mach, G.-K. Plattner, S. K. Allen, M. Tignor, and P. M. Midgley, editors. Cambridge University Press, Cambridge, UK. [online] URL: https://www.ipcc.ch/report/managing-the-risks-of-extreme-eventsand-disasters-to-advance-climate-change-adaptation/

Intergovernmental Panel on Climate Change (IPCC). 2014. AR5 climate change 2014: impacts, adaptation, and vulnerability. Cambridge University Press, Cambridge, UK. [online] URL: https://www.ipcc.ch/report/ar5/wg2/

Kittinger, J. N., E. M. Finkbeiner, N. C. Ban, K. Broad, M. H. Carr, J. E. Cinner, S. Gelcich, M. L. Cornwell, J. Z. Koehn, X. Basurto, R. Fujita, M. R. Caldwell, and L. B. Crowder. 2013. Emerging frontiers in social-ecological systems research for sustainability of small-scale fisheries. Current Opinion in Environmental Sustainability 5(3-4):352-357. https://doi.org/10.1016/ j.cosust.2013.06.008

Knutson, T. R., J. L. McBride, J. Chan, K. Emanuel, G. Holland, C. Landsea, I. Held, J. P. Kossin, A. K. Srivastava, and M. Sugi. 2010. Tropical cyclones and climate change. Nature Geoscience 3 (3):157-163. https://doi.org/10.1038/ngeo779

Kok, M., M. Lüdeke, P. Lucas, T. Sterzel, C. Walther, P. Janssen, D. Sietz, and I. de Soysa. 2016. A new method for analysing socioecological patterns of vulnerability. Regional Environmental Change 16(1):229-243. https://doi.org/10.1007/s10113-014-0746-1

Louisiana Department of Wildlife and Fisheries (LDWF). 2018. 2017-2018 annual report. Louisiana Department of Wildlife and Fisheries, Baton Rouge, Louisiana, USA. [online] URL: http:// www.wlf.louisiana.gov/sites/default/files/pdf/publication/42675-2017-2018annual-report/2017-2018 annual report low-res.pdf

Mackinson, S., D. C. Wilson, P. Galiay, and B. Deas. 2011. Engaging stakeholders in fisheries and marine research. Marine Policy 35(1):18-24. https://doi.org/10.1016/j.marpol.2010.07.003

Macnaghten, P., and M. Jacobs. 1997. Public identification with sustainable development: investigating cultural barriers to participation. Global Environmental Change 7(1):5-24. https://doi. org/10.1016/S0959-3780(96)00023-4

Markantonatou, V., P. Noguera-Méndez, M. Semitiel-García, K. Hogg, and M. Sano. 2016. Social networks and information flow: building the ground for collaborative marine conservation planning in Portofino Marine Protected Area (MPA). Ocean and Coastal Management 120:29-38. https://doi.org/10.1016/j. ocecoaman.2015.11.023 
Marshall, N. A. 2010. Understanding social resilience to climate variability in primary enterprises and industries. Global Environmental Change 20(1):36-43. https://doi.org/10.1016/j. gloenvcha.2009.10.003

Marshall, N. A., D. M. Fenton, P. A. Marshall, and S. G. Sutton. 2007. How resource dependency can influence social resilience within a primary resource industry. Rural Sociology 72 (3):359-390. https://doi.org/10.1526/003601107781799254

Marshall, N. A., and P. A. Marshall. 2007. Conceptualizing and operationalizing social resilience within commercial fisheries in northern Australia. Ecology and Society 12(1):1. https://doi. org/10.5751/ES-01940-120101

Marshall, N. A., R. C. Tobin, P. A. Marshall, M. Gooch, and A. J. Hobday. 2013. Social vulnerability of marine resource users to extreme weather events. Ecosystems 16(5):797-809. https://doi. org/10.1007/s10021-013-9651-6

McClanahan, T. R., S. D. Donner, J. A. Maynard, M. A. MacNeil, N. A. J. Graham, J. Maina, A. C. Baker, J. B. Alemu I, M. Beger, S. J. Campbell, E. S. Darling, C. M. Eakin, S. F. Heron, S. D. Jupiter, C. J. Lundquist, E. McLeod, P. J. Mumby, M. J. Paddack, E. R. Selig, and R. van Woesik. 2012. Prioritizing key resilience indicators to support coral reef management in a changing climate. Plos One 7(8):e42884. https://doi.org/10.1371/journal. pone. 0042884

Melancon, E. Jr., T. Soniat, V. Cheramie, R. Dugas, J. Barras, and M. Lagarde. 1998. Oyster resource zones of the Barataria and Terrebonne estuaries of Louisiana. Journal of Shellfish Research 17(4):1143-1148.

Moser, S. C., and J. A. Ekstrom. 2011. Taking ownership of climate change: participatory adaptation planning in two local case studies from California. Journal of Environmental Studies and Sciences 1(1):63-74. https://doi.org/10.1007/s13412-011-0012-5

O'Brien, K. L., and J. Wolf. 2010. A values-based approach to vulnerability and adaptation to climate change. Wiley Interdisciplinary Reviews: Climate Change 1(2):232-242. https:// doi.org/10.1002/wcc. 30

Ogunyinka, E. O., D. R. Lavergne, and L. Bharadwaj. 2011. Louisiana commercial oyster fishermen: trends in fishing efforts, landings and landing revenue, impact of hurricanes and monitoring of recovery. Louisiana Department of Wildlife and Fisheries, Baton Rouge, Louisiana, USA. [online] URL: http://www.wlf. louisiana.gov/sites/default/files/pdf/page/37774-economic-reports/ tripticketoyster-report.pdf

Penland, S. 1990. Relative sea-level rise in Louisiana and the Gulf of Mexico:1908-1988. Journal of Coastal Research 6(2):323-342. [online] URL: https://www.jstor.org/stable/4297682

Perry, R. I., R. E. Ommer, M. Barange, S. Jentoft, B. Neis, and U. R. Sumaila. 2011. Marine social-ecological responses to environmental change and the impacts of globalization. Fish and Fisheries 12(4):427-450. https://doi.org/10.1111/j.1467-2979.2010.00402. $\underline{\mathrm{x}}$

Preston, B. L., E. J. Yuen, and R. M. Westaway. 2011. Putting vulnerability to climate change on the map: a review of approaches, benefits, and risks. Sustainability Science 6 (2):177-202. https://doi.org/10.1007/s11625-011-0129-1
Sebesvari, Z., F. G. Renaud, S. Haas, Z. Tessler, M. Hagenlocher, J. Kloos, S. Szabo, A. Tejedor, and C. Kuenzer. 2016. A review of vulnerability indicators for deltaic social-ecological systems. Sustainability Science 11(4):575-590. https://doi.org/10.1007/ s11625-016-0366-4

Sen, S., and J. R. Nielsen. 1996. Fisheries co-management: a comparative analysis. Marine Policy 20(5):405-418. https://doi. org/10.1016/0308-597X(96)00028-0

Siegel, K. J., R. B. Cabral, J. McHenry, E. Ojea, B. Owashi, and S. E. Lester. 2019. Sovereign states in the Caribbean have lower social-ecological vulnerability to coral bleaching than overseas territories. Proceedings of the Royal Society B 286:20182365. http://dx.doi.org/10.1098/rspb.2018.2365

Stringer, L. C., A. J. Dougill, E. Fraser, K. Hubacek, C. Prell, and M. S. Reed. 2006. Unpacking "participation" in the adaptive management of social-ecological systems: a critical review. Ecology and Society 11(2):39. [online] URL: http://www. ecologyandsociety.org/vol11/iss2/art39/

Turner, B. L. II, R. E. Kasperson, P. A. Matson, J. J. McCarthy, R. W. Corell, L. Christensen, N. Eckley, J. X. Kasperson, A. Luers, M. L. Martello, C. Polsky, A. Pulshiper, and A. Schiller. 2003. A framework for vulnerability analysis in sustainability science. Proceedings of the National Academy of Sciences 100 (14):8074-8079. https://doi.org/10.1073/pnas. 1231335100

Turner, R. A., N. V. C. Polunin, and S. M. Stead. 2014. Social networks and fishers' behavior: exploring the links between information flow and fishing success in the Northumberland lobster fishery. Ecology and Society 19(2):38. http://dx.doi. org/10.5751/ES-06456-190238

U.S. Census Bureau. 2011. 2010 census demographic profile summary file. U.S. Census Bureau, Washington, D.C., USA. [online] URL: https://www.census.gov/data/datasets/2010/dec/ demographic-profile-with-geos.html 


\section{APPENDIX 1}

\section{Terrebonne Parish Oyster Fishery}

Interview questionnaire

Date

My name is and I am with a team of researchers at University leading a social and economic evaluation of the oyster fishery in Terrebonne Parish (TP). In this project, we are hoping to learn about the social and economic connection people have with oysters and the fishery. This includes how each group/industry uses the resource, and when, where, how, and why. As part of this project, we hope to interview as many resource-users such as you to understand how fishers and their businesses may be affected by changes in environmental conditions. The interview will generally only take about 50 minutes. All of your responses would remain confidential and would be collated in an anonymous way with everyone else's, and you would be able to access the report online. Your participation is entirely voluntary and you are free to not answer any questions that you would prefer not to. I will give you my contact details and you can contact me anytime for more information or if you have any concerns. Do you have any questions at this stage? Would you be happy to participate in this survey?

Let's start...

1. Please list the first words that come to mind when you think of the oyster fishery here in the TP area? (list as many words as you like)

SECTION A. In this section I would like to know a little bit about your operation.

2. Are you a: lease owner + operator

lease owner but not operator

operator only

business owner

other

3. How long have you been in the industry? yrs

4. What other work have you done in the past 5 yrs?

\begin{tabular}{|l|l|l|}
\hline Occupation & Why stop? & Prefer to current job? \\
\hline & & \\
\hline & & \\
\hline
\end{tabular}

5. About how many days in the previous 12 months were you operating (in the TP area)? days

6. How far, on average, do you travel from your home? That is: do you typically fish/work very close to your home or do you tend to roam across the area/region?

very close to home (i.e. $<5 \mathrm{mi}$ ) 
close to home (i.e. $5-10 \mathrm{mi}$ )

roam quite some distance from home $(>10 \mathrm{mi})$

7. Do you use multiple ports/docks? Y / N

8. Do you use multiple boats/operators? Y / N

9. Which fisheries do you operate in?

oyster

shrimp

crawfish

crab

finfish (species:

other

10. What types of gear do you use for each fishery?

oyster $=$

shrimp $=$

crawfish $=$

$\mathrm{crab}=$

other $=$

finfish $=$

11. Which fishery contributes most to your income? Please rank all appropriate fisheries. oyster shrimp crawfish crab finfish (species: other

SECTION B. In this section I would like to know a bit more about your relationship with the oyster fishery. When I refer to the oyster fishery, I mean all aspects, from fishing to processing and selling oysters. I also mean all land and water from the bayous, the ponds, the open waters, and of course the oyster leases.

For the next group of questions, I'll read out a list of statements, and I'd like you to rate your agreement or disagreement with each statement, using a ten-point scale where: $1=$ Very Strongly Disagree, and 10 = Very Strongly Agree.

How much do you agree or disagree with each of these statements:

\section{A) Susceptibility}

12. There are many other places that are better than the TP area for oyster fishing

13. The TP area and oysters are part of my identity

14. I wouldn't want to be anything other than a

15. The fishing industry to me is not just a job - it is my lifestyle (insert appropriate occupation)

16. I plan to still be a (insert appropriate occupation) in five years time

17. I live in this area because of the fishing/opportunity

18. I plan to be resident of this area in the next five years

19. I am likely to remain operating in this region if events such as hurricanes and oil spills occur more frequently

20. I value oysters because they support a variety of life such as fish, invertebrates

21. I value oysters because they support a desirable and active way of life

22. I value oysters because we can learn about the environment through them 
23. I value oysters because they provide a source of income

24. Oysters are a great asset for the economy of the TP area

25. Oysters in the TP area contribute to my quality of life and well-being

26. The aesthetic beauty of the TP area is outstanding

27. The oyster (reefs) that I (or my boats) fish the most are in great condition

28. I feel optimistic about the future of the oyster reefs in the TP area

29. Oysters in the TP area are or were in their best condition: now / $5 \mathrm{yr}$ ago / $10 \mathrm{yr}$ ago /

25 yr ago / 50 yr ago / don’t know

30. What do you think are the THREE most serious threats to oysters in the TP area?

a

$\mathrm{b}$

c

31. I feel confident the oyster fishery is well managed in the TP area

32. I support the current rules and regulations that affect access and use of oyster reefs in the TP area

33. I am optimistic about the future of my business in the TP area

34. My business has not performed this year as well as it did last year

35. I do have fair access to the oyster reefs/leases in the TP area compared to other user groups

36. I would like to do more to help protect and ensure a sustainable future for oysters in the TP area

37. I would be personally affected if the health of the oysters in the TP area declined

38. I regularly get involved in research and/or management decisions for the oyster fishery in the TP area

39. I can make a personal difference in improving the health of the oysters in the TP area

40. I try to encourage other people to reduce their impacts on oysters in the TP area

41. It is my responsibility to protect oysters in the TP area

42. Commercial fishers should take steps to reduce their impacts on oysters in the TP area

43. It is the responsibility of all Louisianans to protect oysters

B) Adaptive Capacity

44. I am confident things will turn out well for me regardless of future events such as hurricanes, oil spills, or diversions

45. I am uncertain how to plan for changes in the TP area that may affect me such as hurricanes, oil spills, or diversions

46. I am good at developing scenarios of the future of my business and planning for them

47. I discuss new ways of solving problems associated with my business with others 
48. I am more likely to adapt to changes as a result of hurricanes, oil spills, or diversions compared to other coastal residents I know

49. I have planned for my financial security

50. I am interested in learning how to better prepare my business for significant events, such as hurricanes, oil spills, and diversions

53. Do you $(\mathrm{Y} / \mathrm{N})$ ?

a. have fuel efficient engines

b. have green energy, such as solar panels, for any part of your business

c. use alternative fuels such as biodiesel or ethanol

d. participate in a shell recycling program

54. On a scale of 1-10, how much do you trust the information you receive about the oyster fishery in the TP area from the following groups
a. friends, family, and colleagues
b. LDWF, gov't officials (e.g. CPRA)
c. academic research institutions (e.g. LSU, LA Sea Grant)
d. industry groups/representatives (e.g. Oyster Task Force)
f. media (e.g. radio, newspapers, tv)
h. other commercial fishers

\section{C) Personal Info}

Demographics

55. Would you mind telling me...

a. What year you were born? 19

b. What is your current home postcode?

c. How many years you have lived in the TP area (i.e. Terrebonne Parish)? __ yrs

d. How many years you have operated in the TP area? yrs

e. Are you currently married or have a partner? Y / N

f. Do you have any dependent children? Y / N

g. Do you have university/college education (i.e. beyond high school)? Y / N

h. What proportion of your household income came from commercial fishing in the last financial year? _ \%

i. What proportion of your fishing income was from the TP area? _ $\%$

Business related information

56. Do you mind telling me your business turnover (entire revenue), for the past 12 months, in broad categories (read out)
a. $<\$ 20,000$
b. $\$ 20,000$ to $\$ 60,000$
c. $\$ 60,000$ to $\$ 100,000$
d. $\$ 100,000$ to $\$ 200,000$
e. $\$ 200,000$ to $\$ 300,000$ 
f. $\$ 300,000$ to $\$ 500,000$

g. $>\$ 500,000$

57. How many employees (full time equivalents) did your business employ over the previous 12 months?

58. How many of your family members are also in your business/commercial fishers?

59. Do you have business insurance? Y / N

60. Do you have vessel insurance? Y / N

61. How old, on average, is/are your vessel(s)? _ _ yrs

62. Do you have any form of technology for your vessel(s) (e.g. GPS, sonar)? Y / N

63. What proportion of your product do you sell in:
a. the local region:
c. in the USA: $\%$
b. elsewhere in LA:
d. internationally: _ \%
e. don't know: _ \%

64. What proportion of your product do you sell directly to different market types such as:
a. wholesalers: $\%$
b. retailers: $\%$
c. restaurants: _ \%
d. members of the public: $\%$
e. other, $: \quad \%$

65. If you are a non-operator, can I contact the person(s) who is operating your vessel/license, so their views can also be included (get contact details if Y)? Y / N

66. Would you mind if I contacted you again for future surveys (get contact details if N)? Y / N 67. Would you like my contact details? Y / N

Thank you for your time!

Notes/contact details: 


\section{APPENDIX 2}

\section{Tables}

Table S1. Factor loadings for each susceptibility indicator on PCA axes. Factor loadings greater than 0.4 (bold) on any given principal component are generally considered to contribute substantially to that component.

\begin{tabular}{lll}
\hline Susceptibility indicator & PC1 & PC2 \\
\hline Access & $\mathbf{- 0 . 5 5 6}$ & $\mathbf{- 1 . 5 0 3}$ \\
Motivation to change & $\mathbf{0 . 5 1 6}$ & 0.257 \\
Norms & $\mathbf{0 . 1 1 1}$ & 0.139 \\
Occupational identity & $\mathbf{- 0 . 4 0 7}$ & $\mathbf{0 . 7 3 8}$ \\
Perceptions of environment & $\mathbf{0 . 7 2 6}$ & 0.189 \\
Perceptions of management & 0.136 & $\mathbf{- 0 . 8 7 9}$ \\
Personal attachment & -0.104 & 0.196 \\
Personal identity & -0.374 & 0.158 \\
Stewardship & $\mathbf{0 . 6 4 8}$ & 0.061 \\
Values & $\mathbf{0 . 6 4 2}$ & 0.101 \\
Well-being & $\mathbf{- 1 . 3 3 7}$ & $\mathbf{0 . 5 4 3}$ \\
\hline
\end{tabular}

Table S2. Absolute factor loadings, weights, and normalized weights of each susceptibility indicator on PCA axes.

\begin{tabular}{lllll}
\hline Susceptibility indicator & PC1 & PC2 & Weight & $\begin{array}{l}\text { Normalized } \\
\text { weight }\end{array}$ \\
\hline Eigenvalues & $\mathbf{0 . 5 7 1}$ & $\mathbf{0 . 3 7 8}$ & & \\
Access & 0.556 & 1.503 & 0.886 & 0.178 \\
Motivation to change & 0.516 & 0.257 & 0.391 & 0.079 \\
Norms & 0.111 & 0.139 & 0.116 & 0.023 \\
Occupational identity & 0.407 & 0.738 & 0.511 & 0.103 \\
Perceptions of environment & 0.726 & 0.189 & 0.486 & 0.098 \\
Perceptions of management & 0.136 & 0.879 & 0.410 & 0.082 \\
Personal attachment & 0.104 & 0.196 & 0.134 & 0.027 \\
Personal identity & 0.374 & 0.158 & 0.274 & 0.055 \\
Stewardship & 0.648 & 0.061 & 0.393 & 0.079 \\
Values & 0.642 & 0.101 & 0.405 & 0.081 \\
Well-being & 1.337 & 0.543 & 0.969 & 0.195 \\
\hline
\end{tabular}


Table S3. Factor loadings for each adaptive capacity indicator on PCA axes. Factor loadings greater than 0.4 (bold) on any given principal component are generally considered to contribute substantially to that component.

\begin{tabular}{lll}
\hline $\begin{array}{l}\text { Adaptive capacity } \\
\text { indicator }\end{array}$ & PC1 & PC2 \\
\hline Buffers & $\mathbf{- 0 . 6 8 8}$ & 0.043 \\
Interest in adapting & $\mathbf{0 . 9 4 1}$ & $\mathbf{0 . 7 4 9}$ \\
Planning & $\mathbf{- 1 . 0 4 8}$ & 0.291 \\
Risk perception & 0.363 & $\mathbf{- 1 . 4 1 9}$ \\
Trust & $\mathbf{0 . 4 3 2}$ & 0.337 \\
\hline
\end{tabular}

Table S4. Absolute factor loadings, weights, and normalized weights of each adaptive capacity indicator on PCA axes.

\begin{tabular}{lllll}
\hline $\begin{array}{l}\text { Adaptive capacity } \\
\text { indicator }\end{array}$ & PC1 & PC2 & Weight & $\begin{array}{l}\text { Normalized } \\
\text { weight }\end{array}$ \\
\hline Eigenvalues & $\mathbf{1 . 0 7 7}$ & $\mathbf{0 . 5 9 6}$ & & \\
Buffers & 0.688 & 0.043 & 0.766 & 0.141 \\
Interest in adapting & 0.941 & 0.749 & 1.459 & 0.269 \\
Planning & 1.048 & 0.291 & 1.301 & 0.240 \\
Risk perception & 0.363 & 1.419 & 1.237 & 0.228 \\
Trust & 0.432 & 0.337 & 0.665 & 0.123 \\
\hline
\end{tabular}




\section{Figures}

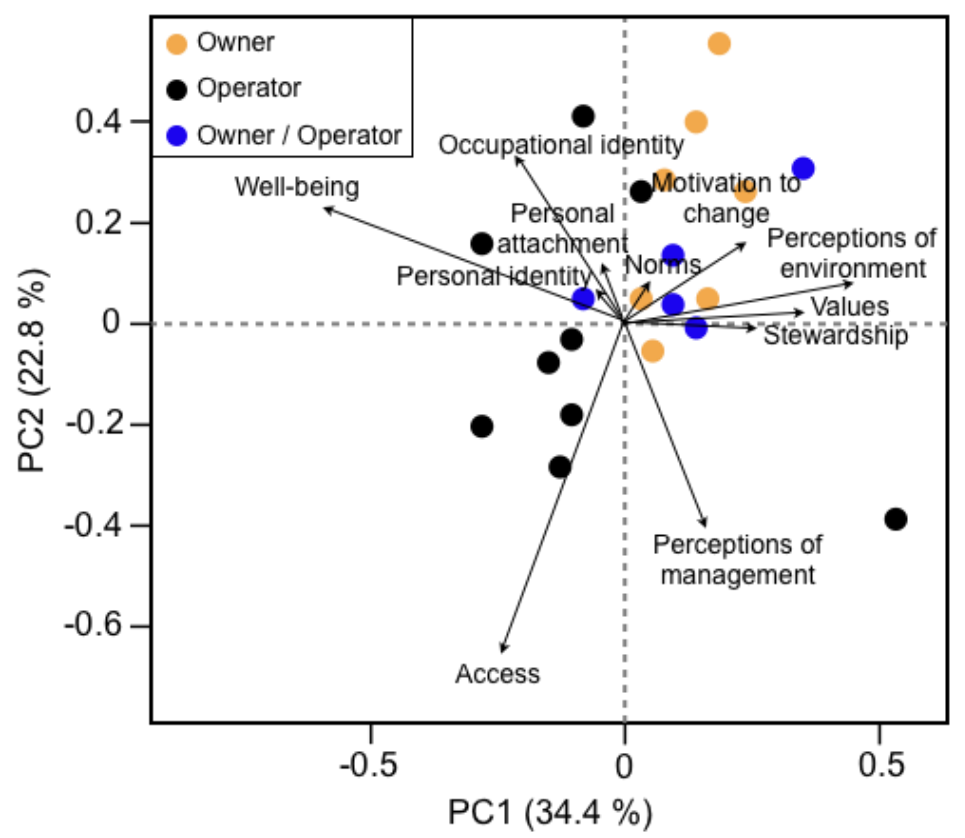

Figure S1. PCA of the 11 susceptibility indicators at the individual level.

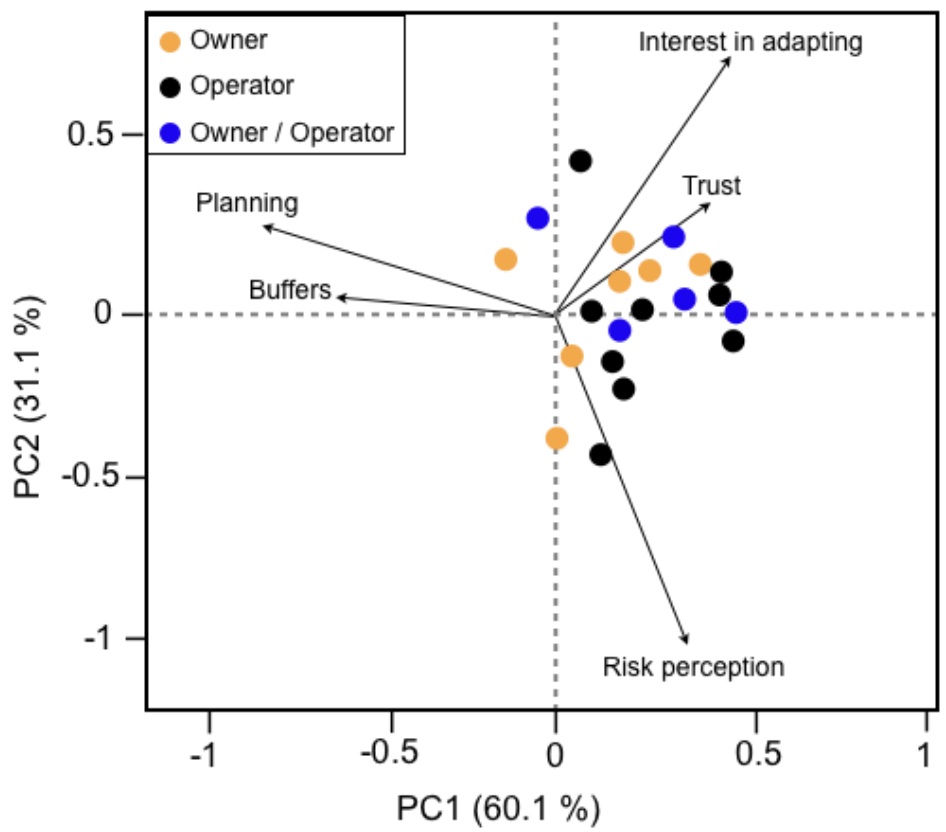

Figure S2. PCA of the 5 adaptive capacity indicators at the individual level. 